\title{
Perspectivas para el Plan Arias en E1 Salvador y Guatemala*
}

Cualquier debate sobre América Central debe comenzar por reconocer que los Estados Unidos tienen intereses nacionales vitales en la región. Más de la mitad del comercio exterior de los Estados Unidos pasa a través de la Bahía del Caribe; por lo tanto, las vías ruarítimas en y alrededor del Canal de Panamá deben permanecer libres. Además, los Estados Unidos tienen intereses de seguridad vitales en el istmo de América Central y no pueden tolerar una amenaza directa a sí mismos o a sus aliados en la región.

En orden de poder asegurar sus intereses en América Central, el objetivo principal de la política norteamericana en la región debe ser el de alentar la evolución de instituciones políticas democráticas. La razón es simple: sólo las instituciones civiles, democráticas, pueden proveer una base duradera para la estabilidad y la paz. Y sólo la estabilidad y la paz asegurarían que América Central no esté sujeta a intervenciones extranjeras no deseadas. Nadie discutiría que construir instituciones democráticas en América Central será una tarea fácil. Casi todos loz países de la región tienen largas historias de regímenes opresivos y autoritarios. Más aún, la habilidad de los Estados Unidos para modelar los eventos es limitada. Sin embargo, a mi juicio, este país no puede contentarse con medidas a medias. No podemos aceptar una situación en la cual. la existencia de instituciones formales democráticas -como una legislatura y un presidente elegidos- oculte el hecho de que el poder real no ésté en manos de civiles democráticos. La democracia meramente formal puede, en la práctica, ser sólo marginalmente mejor que un rëgimen autoritario.

A mi juicion, el Plan Arias significa una valiosa oportunidad de practicar nuestros intereses al alentar el proceso de reconciliación

* Artfculo preparado por el Director del Programa de Estudios Latinoamericanos, School of Advanced International Studies de la Johns Hopkinis University, basado en su declaración ante el Subcomité de Asuntos del Hemisferio Occidental del Comité de Asuntos Exteriores de la Gámara de Representantes de los Estadós Unidos de América," del "2l de octubre de 1987 en Washington, D. C. 
nacional y el fortalecimiento de las instituciones democráticas. Habiendo nacido a la luz de las iniciativas de paz del Grupo Gontadora, el Plan Arias es una extensión lógica de los esfuerzos diplomáticos que se han estado efectuando por años en la región. En sólo dos meses y medio se han logrado importantes - aunque limitadosprogresos hacia un arreglo de paz regional basado en principios democráticos. En mi opinión, aún si el Plan Arias sólo logra algunos de sus objetivos, la designación del Premio Nobel de la Paz el año 1987 al Presidente de Costa Rica, Oscar Arnulfo Arias, el autor principal del Plan, es un honor bien merecido.

El Congreso, y su Comité de Asuntos Exteriores, han vertido gran parte de su atención a Nicaragua y a la participación de ese país. en el Plan Arias, el cual, rin embargo, es un programa regional; si ha de tener un resultado en cualquiera de los países centroamericanos, debe tenerlo en todos ellos. Me gustaría, por lo tanto, Ilamar la atención hacia dos firmantes del acuerdo - paises que hoy en día son generalmente pasados por alto- El Salvador y Guatemala.

\section{El Salvador}

Tres años después de la elección del Presidente José Napoleón Duarte, El Salvador continúa siendo asolado por la violencia polftica. Allí la guerra civil ha durado más, y probablemente durará mucho más aún, que la guerra de los contras en la vecina Nicaragua. Ya han muerto más de 60.000 personas -más del uno por ciento de la población del país- y el 25 y quizás el 30 por ciento de la población está desplazada.

A la luz de su riesgosa situación, El Salvador ha sido una preocupación prioritaria de la política norteamericana durante los últimos seis años. Desde 1981, El Salvador ha recibido 2.500 millones en ayuda norteamericana, haciendo de él, después de Egipto e Israel, el tercer receptor más grande de ayuda exterior norteamericana. Más aún, a pesar de que la participación directa de tropas norteamericanas ha sido baja, El Salvador representa uno de los más grandes esfuerzos de contrainsurgencia apoyados por los Estados Unidos desde la Guerra de Vietnam.

Aún así, a pesar de la ayuda masiva y de la mejor actuación de los militares salvadoreños, no se vislumbra el fin de la guerra.: En 1984, oficiales norteamericanos predijeron que el conflicto duraría otros cuatro años. En 1986, esta estimación fue modificada a cinco años. En 1987 fue revisada una vez más. Se calcula que el conflicto en El Salvador durará otros siete a diez años.

De acuerdo a estas poco auspiciosas predicciones para la nación, el Presidente Duarte demostró tener imaginación y liderazgo al fir- 
mar $-\mathrm{y}$, luego, tomar medidas para implementar- el Acuerdo de Guatemala. El Acuerdo no requiere específicamente negociaciones entre los gobiernos y los grupos guerrilleros armados. Pero en el espíritu del Acuerdo, representantes de la guerrilla y el gobierno se reunieron en San Salvador el 4 de octubre de 1987. El Salvador, sin embargo, a diferencia ide otros firmantes del Plan, ya tenía un precedente de diálogo con la oposición armada. Representantes del gobierno y de la guerrilla se reunieron por primera vez en la villa de La Palma el 15 de octubre de 1984, y un mes después en Ayagualo.

Como resultado de estas últimas conversaciones, el gobierno y las guerrillas han acordado formar dos comisiones adjuntas de cuatro miembros, encargadas de llevar a cabo estipulaciones específicas del Plan Arias. Los arreglos para un cese del fuego, planificado para ser puesto en práctica el 7 de noviembre de 1987, ya están en su lugai.

Más aún, bajo los términos del Acuerdo, 4.000 refugiados que viven en - el campo de refugiados de Mesa Grande, en Honduras, fueron repatriados el 10 de octubre a sus hogares en El Salvador. La repatriación de refugiados representa el logro más concreto, hasta la fecha, del Pres:dente Duarte bajo el Plan Arias. La mayor parte de estos refugiados habían dejado El Salvador entre 1980 y 1983 bajo un severo programa de contrainsurgencia militar que buscaba vaciar las zonas de guerra de todos los posibles simpatizantes de la guerrilla. La repatriación de refugiados - muchos de ellos a regiones con act vidades guerrilleras significativas- representa una importante - aun cuando involuntaria- concesión de los militares. Sin embargo, las organizaciones de derechos humanos y grupos de Iglesia han expresado temor de que una vez que la atención interracional en el proce-o de repatriación șe diluya, los militares puedan recurrir una vez más a medidas represivas.

Estos esfuerzos de parte de El Salvador para cumplir el Acuerdo de Guatemala son positivos y dignos de atención. Es conveniente que el Comité de Asuntos Exteriore; del Congreso los apoyen y controlen de cerca.

Sin embargo, creo que un análisis desapasionado de la situación política en El Salvador sugeriría que la implementación total del Plan Arias es poco probable.

EI conflicto actual en El Salvador - que se remonta, aproximadamente, a fines de $10 \cdot 70$ - tiene profundas raíces socio-económicas, Entre los años 60 y 70, la economía salvadoreña creció rápidamente por medio de la expansión agrícola e industrial altamente intensiva de capitales. Mientras que la productiv:dad laboral y las exportaciones agrícolas se incrementaban aceleradamente, las ganancias no eran equitativamente distribuidas a todos los sectores de la 
sociedad salvadoreña. El desempleo creció y los sueldos disminuyeron. El resultado fue la tenencia altamente concentrada de tierras y la marginalización social de gran parte de la población. Los campesinos sin tierras, por ejemplo, aumentaron del $11 \%$ de la población de EI Salvador en 1961 al $40 \%$ en 1975 . Ya que Ios sueldos reales disminuyeron, las labores temporales de los migrantes se convirtieron en la forma dominante de empleo en la economía rural.

La marginalización de los trabajadores y campesinos salvadoreños en los años 60 y 70 dio como resultado un amplio movimiento por profundas reformas sociales. Más aún, llevó a la formación de una cantidad de grupos de guerrilla revolucionaria. Trágicamente, el gobierno no fue capaz de acomodar ni siquiera modestas medidas reformistas. Los sindicato ide campesinos y trabajadores que podrían haber sido guiados a un proceso político democrático normal fueron radicalizados.

En respuesta a estas presiones, una coalición moderada de reformistas civiles y militares derrocó al gobierno del General Carlos Humberto Romero en octubre de 1979. Tres meses después, la Junta Reformista había caído bajo la presión de los oficiales conservadores del ejército. Siguió un período de severa represión, en el cual miles de supuestos izquierdistas fueron asesinados.

Después de varios años de incertidumbre, cuando parecía que los elementos de extrema derecha dominarían el proceso político, la presión y ayuda de los Estados Unidos pudo hacer posible la elección de 1984 en El Salvador. José Napoleón Duarte fue el ganador en esa elección. . Pero es imperativo que entendamos que Ia elección de Duarte fue sólo el comienzo -no el final- de un proceso de transición democrática. Muchos de los problemas institucionales y estructurales en El Salvador que hicieron tan tortuosa aquella transición permanecen aún hoy en su lugar. Es posible que estos problemas estructurales vayan a limitar las posibilidades para la futura consolidación de la democracia y para la aplicación exitosa del Plan Arias en EI Salvador. Los problemas más significativos son: 1) el poder de las fuerzas conservadoras en la política salvadoreña y 2) la influencia de las fuerzas armadas sobre las instituciones civiles.

El poder de las fuerzas conservadoras en la vida política de El Salvador se evidencia en el fracaso de la reforma agraria. En un pais $\tan$ dependiente de la agricultura como es E1 Salvador, la redistribución de la tierra es la llave para cualquier programa de reformas. Pero la élite terrateniente salvadoreña se ha resistido largamente a cualquier esfuerzo -no importa cuán modesto- de redistribuir el dominio de las tierras. La tierra es para ellos no sólo la única fuente de sus riquezas. También es la base de su prestigio social. Por lo tanto, se niegan a cualquier cambio. Y estạn dispues- 
tos a hacer casi cualquier cosa para parar los esfuerzos reformadores.

Se comenzó un modesto plan de reforma agraria en 1980, bajo un gobierno de transición. Este programa en la actualidad ha afectado a menos del $20 \%$ de todas las familias campesinas. Bloqueado por los grandes terratenientes salvadoreños, el gobierno de Duarte ha sido incapaz de profundizar los efectos de la reforma agraria. En especial, la Fase ri del programa, que afectaría a las grandes plantaciones de café, no ha sido aún llevada a cabo.

$\mathrm{E} I$ asunto de las tierras es el elemento central de las condiciones socio-económicas altamente desiguales que continúan asolando a EI Salvador. Esas condiciones fueron agravadas por un cambio en las políticas gubernamentales en 1986. En enero del mismo año, Duarte adoptó medidas económicas de austeridad ampliamente impopulares, que cayeron más duramente sobre los campesinos y las clases obreras de El Salvador. Los precios de los bonos de alimentación, tales como los de arroz y poroto", se triplicaron en el curso de un año. A pesar de que los sueldos -más notoriamenté en el sector público- se han incrementado, el costo de la vida se ha más que duplicado desde que Duarte asumió la Presidencia. La situación empeoró con el terremoto que aroló San Salvador en octubre de 1986, que dejó más de 100.000 personas sin hogar.

Las condiciones que estoy describiendo deben ser vistas en el contexto de una nación que ha soportado casi ocho años de guerra civil. Los esfuerzos del Presidente Duarte para distribuir las cargas de la guerra en forma más equitativa han recibido la oposición de las fuerzas intransigentes de la derecha. Por ejemplo, a principios del año 1987 y durante cuatro meses !os partidos políticos de derecha boicotearon las sesiones de la Asamblea Legislativa para protestar por las nuevas medidas impositivas auspiciadas por el gobierno de Duarte.

Como resultado de tal obstrucción, ha sido diffćil, si no imposible, para el Presidente, llevar a cabo las medidas de reforma social que prometió en su campaña inicial en 1984. Este fracaso ha facilitado la inestabilidad interna, una situación que podrla eventualmente funcionar para minar las instituciones democráticas del $\mathrm{E}_{5}$ tado. Por ejemplo, las huelgas y manifestaciones obreras se han vuelto más militantes y de confrontamiento, y ha crecido la oposición entre muchos grupos que previamente apoyaban al Partido Demócrata Cristiano de Duarte.

El segundo -y más inquietante- impedimento estructural para las reformas son los militares. Habiendo recibido más de us\$ 600 millones en ayuda militar directa, las fuerzas armadas salvadoreñas dependen casi totalmente de Ios equipos y recursos suministrados por los norteamericanos. A pesar de que los Estados Unidos han tomado medidas altamente necesarias para modern'zar y profesion?- 
lizar a las fuerzas armadas, no han tenido éxito en persuadirlas de aceptar principios básicos como el respeto por el control civil.

Cuando los Estados Unidos incrementaron la ayuda al gobierno de El Salyador a princ:pios de los 80, el Congreso tuvo la sabiduría de recomendar que la ayuda a las fuerzas armadas fuera condicionada por el progreso verificable en detener las violaciones a los derechos humanos. Como resultado de esto, hubo una notable disminución de las muertes civiles. Sin embargo, los Estados Unidos no debieran estar excesivamente orgullosos en este sentido. Aún ocurren desapariciones inexplicadas y asesinatos de líderes de la oposición. Más aún, sólo unos poco: de los miembros de los escuadrones de la muerte han sido procesados. La oposición política en El Salvador opera bajo la amenaza implícita de que los escuadrones de Ja muerte podrían ser rápidamente reactivados.

Ahora que la ayuda norteamericana a los militares salvadoreños ha hecho imposible pensar en un derrocamiento vio'ento por parte de los insurgentes de izquierda, las exigencias militares no pueden seguir aportando excusas para los abusos en lo: derechos humanos. Los Estados Unidos debieran unir la asistencia militar continuada a un nivel no ambiguo de respeto por los derechos humanos.

Muchos observadores argumentan que un significativo cambio ideológico y generacional en el cuerpo de oficiales de las fucrzas armadas salvadoreñas promete hacer más dificil el trato con los militares salvadoreños en un futuro cercano. Un grupo más antiguo -quienes continúan trabajando principalmente con los norteamer:canos para llevarse bien con ellos- está siendo sobrepasado por una generación más joven y auto uficiente, que bordea los 40 añoś. El grupo más joven está al mando de lạ tropas de combate en el campo de batalla. Han recibido un extensivo entrenamiento con* trainsurgente de los norteamericanos. Pero no está para nada claro si abrazan ideales democráticos n si aceptan el control civil sobre lo que ellos consideran temas militares $y$ de seguridad vitales, tales como Ja guerra civil euerrillera. De acuerdo con un reportaje que apareció en el Miami Herald el 3 de agosto de 1987:

... "permanece aún la pregunta acerca de si, con la asistencia militar norteamericana condicionada a un gobierno civil, han aprendido simplemente las palabras (democracia y derechos humanos). Incluso algunos partidarios de la política exterior norteamericana se preocupan de si Ios Estados Unidos, al reformar la autoimagen del cuerpo de oficiales junto con las formas de Iucha, no ha creado un monstruo que ningún civil será capaz de controlar".

El contacto con los E-tados Unidos y nuestro ethos militar no parece haber tenido demasiado impacto. Este grupo parece tener 
una mentalidad diferente. Ellos-creen que el objetivo de la victoria en la guerra de guerrillas es un bien absoluto que debiera ser perseguido aún dejando de lado los otros objetivos. Por lo tanto, c.esconfían de los esfuerzos de paz del Presidente Duarte. Son desdeñosos del gobierno norteamericano en la medida en que los Estados Unidos apoyan el gobierno constitucional y respetan los derechos humanos. Ellos creen que el respeto a la democracia implica un beneplácito hacia las guerrillas marxista. Es mejor, a su juicio, erradicar tanto a los sospechosos de ser rebelde; como a los de ser simpatizantes.

Esa mentalidad coincide con los intransigentes de la élite acomodada. La élite piensa que las reformas sociales más modestas son equivalentes a la revolución marxista. Los esfuerzos de Duarte por llevar a cabo las demandas rebeldes son, desde su perspectiva, traición. Aun cuando los militares han estado implicados en una-serie de raptos de cindàdanos adinerados para cobrar rescate, la afinidad entre los militares y la élite económica permanece fuerte. Ertán de acuerdo en que es necesario: detener a los rebeldes con todas las fuerzas que sean necesarias; bloquear las reformas, que 'olo fortalecerán las demandas por más reformas; y buscar hacerle el juego a Estados Unidos para mantener el apoyo militar norteamericano y el apoyo a la balanza de pago", s'n aceptar Jos valores básicos norteamericanos.

Es poco probable que las generaciones más jóvenes de oficiales intenten tomar el poder a través de un golpe militar. Están conscientes de que tal acto podría poner en jaque los futuros embarques de ayuda militar norteamericana. Pero el verdadero problema es el creciente poder e influencia que están ganando estos oficiales sobre él marco constitucional de los gobiernos civiles. ¿Tienen ellos un "veto" sobre el régimen civil? Muchos observadores arí lo piensan.

Si algunos de los pasos iniciales dados por el Presidente Duarte para cumplir con el Plan Arias fueron creativos e independientes, otro", yo diría, han sido distorsionados por el enorme poder de la élite económica y de los militares en El Salvador. Por ejemplo. a pesar de que el Acuerdo de Guatemala no requiere que el gobierno hable con los rebeldes armados, sí requiere que el gobierno converse con la oposición política desarmada del país, y que forme una Comisión Nacional de Reconciliación para incluir a representantes de los grupos de oposición. Sin embargo, los nombramientos de Duarte a la Comisión Nacional de Reconciliación fueron cargados a favor de la centro-derecha y la derecha del espectro político. Sólo un nombramiento àlternativo podría ser clasificado como de izquierda democrática; ni pensar en las fuerzas rebeldes. Mientras que las comparaciones entre países pueden llevar a confusión, los nombramientos de la Comisión Nacional de Reconciliación en Nicaragua 
parecen ser más de centro y balanceados, aun cuando fueron nombrados por el Presidente sandinista Daniel Ortega.

También surgen algunas ambigüedades con respecto al cumplimiento que da EI Salvador al llamado a la "democratización" que hace el Plan Arias. Los arrestos arb:trarios, los asesinatos, y la desaparición hacen todavía que la oposición pacífica al gobierno sea una empresa peligrosa. Como resultado, aunque es cierto, por ejemplo, que no existen mecanismos formales de censura de prensa, los periódicos y estaciones de radio de la oposición que fueron perseguidos y cerrados en 1980 y 1981, aún permanecen cerrados. Desafortunadamente, incluso el gobierno del Partido Demócrata Cristiano ha inflamado el clima de intolerancia por tener puntos de vista políticos distintos. Frecuentemente ha denunciado a sindicatos de la oposición y a otros grupos políticos de ser enemigos del Estado.

En una importante prueba de cuán lejos irá El Salvador para abrir su espacio político, Rubén Zamora, un líder en el exilio del Frente Democrático Revolucionario (FDR), planea regresar a San Salvador en forma permanente, antes de la fecha límite del 7 de noviembre puesta por el Plan Arias. A pesar de que está aliado con el predominantemente marxista-leninista Frente Farabundo Martf de Liberación Nacional (FMLN), el FDR fue formado en 1980 como una alianza de los socialdemócratas, democratacristianos disidentes y profesionales de clase media en oposición al gobierno militar. Muchos de sus líderes, incluyendo al hermano del señor Zamora, fueron muertos en una ola de represión militar brutal que, de acuerdo a la oficina de derechos humanos de la Arquidiócesis, dejó decenas de miles de muertos. Aún en el clima político más abierto creado por el Plan Arias, dados los antecedentes sobre derechos humanos de El Salvador, el retorno de Zamora tendría que ser visto como un acto de extraordinaria valentía.

Mientras debiéramos alentar el regreso de líderes políticos exiliados, no debiéramos ser ingenuos con respecto a las motivaciones de Ios más radicales y del FMLN armado. Los guerrilleros han exigido compartir el poder como una condición para detener la guerra. A su vez, el gobierno ha insistido en que los insurgentes deben renunciar a la violencia y deponer las armas, con anterioridad a su participación en las elecciones planeadas para 1988 y 1989. Esta exigencia, sin embargo, sólo tiene sentido si el gobierno puede garantizar la seguridad física de Ios guerrilleros a medida que se reintegren al proceso político. Quizás una invitación créble de parte del gobierno al FMLN para participar en el proceso político pueda tener el efecto de dividir a los líderes de la legítima oposición democrática en el FDR de los extremistas jdeológicos del FMLN. Si el 
FMLN rehusara participar en un proceso político abierto, serfan aislados como radicales incorregibles.

Hay serios obstáculos en El Salvador para cumplir el plan de paz Arias. Sin embargo es una iniciativa digna de ser continuada. $\mathrm{Ha}$ puesto en marcha fuerzas que están empujando a El Salvador por caminos que llevan a la reconciliación nacional. Este movimiento suma fuerzas al proceso de democratización iniciado con la elección del Presidente Duarte.

\section{Guatemala}

En Guatemala, el papel de la ayuda e influencia norteamericana, en años recientes, ha sido mucho menor. Como tal, nuestra habiliclad para ejercer influencias es más limitada, y las opciones políticas que enfrentamos son menos diver as. Quizás la mejor manera de aproximarse al nuevo gobierno electo en Guatemala es mantener en mente las lecciones de nuestra experiencia con las fuerzas armadas en El Salvador.

Guatemala, como El Salvador, es una nación con una larga y conflictiva historia de regímenes militares represivos. El golpe de Estado apoyado por la cIA que derrocó al gobierno democrático de Jacobo Arbenz en 1954, marcó el comienzo de un largo período de gobierno militar, que sólo fue interrumpido entre 1966 y 1970. EI I4 de enero de 1986, Vinicio Gerezo, democratacristiano, comenzó otro intento de ejercer un gobierno civil democrático. Sin embargo, existen razones para permanecer escépticos sobre cuán lejos llevará Cerezo el proceso de democratización. Al comienzo de su presidencia, el mismo Gerezo reconoció que los militares tenían un control decisivo sobre las instituciones civiles. Ha habido pocos cambios fundamentales desde entonces que sirvieran para modificar aquella afirmación de Cerezo. No habrá, por ejemplo, juicios de oficiales de las fuerzas armadas por abusos de los derechos humanos en el pasado, a pesar de que hasta 100.000 guatemaltecos podrfan haber sido muertos bajo el régimen militar entre 1975 y 1986. Más aún, Cerezo ha sido incapaz de reorganizar el G-2, la notoria unidad de inteligencia militar que dirigió gran parte de la represión.

Como en El Salvador, la violencia política en Guatemala surgió como respuesta a una rígida estructura económica y polftica que rehusó realizar ni siquiera pequeñas medidas reformistas. El $2 \%$ de la población posee aproximadamente el $70 \%$ de la tierra cultivable, controlando las exportaciones de café, algodón, azúcar y plátanos, que producen la mayor parte del ingreso nacional. A pesar de que el Producto Nácional Bruto per capita sobrepasa los us\$1.000 anuales, tres cuartos de la población ganan menos de us\$300 al año. La mitad de la población no puede cubrir sus necesidades básicas, y 
las cifras de desnutrición son unas de làs más altas èn el hemisferio, segundos después de Haití.

También, como en El Salvador, los militares en Guatemala han servido a los intereses 'económicos y sociales de los privilegiados. Lua clase influyente y los militares se han unido para bloquear las reformas, erradicar a los opositores legítimos y para aterrorizar a la mayorfa de los habitantes. La elección del Presidente Cerezo, como la deI Presidente Duarte, representa un nuevo comienzo que los Estados Unidos deben apoyar. Pero, dado el poder enraizado de la élite económica y de las fuerzas armadas en Guatemala, no deb'éramos hacernos ilusiones de que el éxito de Cerezo esté asegurado:

Sin embargo, si Cerezo está restringido por los militares en su polf́tica interior, ha mostrado más independencia en el área de la volf́tica exterior. Cerezo jugó un importante papel en la formulación del Acuerdo Regional representado en el Acuerdo de Guatemala. $Y$ también ha tomado la iniciativa en proponer un Parlamento Centroamericano, un hecho positivo que los Estados Unidos debieran recibir bien.

En Guatemala, el Plan Arias ha significado un paso digno de mencionar. EI gobierno de Cerezo abrió conversaciones de paz directamente con los representantes de las guerrillas izquierdistas del país el 7 de octubre de 1987, por primera vez desde 1966. Por razones de seguridad, las conversaciones se llevaron a cabo en un lugar no revelado en. Madrid, España, y finalizaron luego de tres días y, como se suponía, con posiciones demasiado separadas para alcanzar cualquier acuerdo concreto. EI fracaso para cumplir con el Plan de Paz en Guatemala, sin embargo, no será culpa de su Presidente, sino un reflejo de la política nacional profundamente dividida en ese país. Los intereses económicos y sociales ya establecidos en Guatemala no quieren "paz"; quieren victoria. Sin embargo, ya que poco se ha hecho por enfrentar las desiguales condiciones sociales que desencadenaron la revolución; el movimiento guerrillero en Guatemala probablemente durará indefinidamente. Como resultado, los guatemaltecos serán privados tanto de paz como de victoria por mucho tiempo más.

$Y_{a}$ que la ayuda militar a Guatemala fue de sólo tres millones de dólares este año, va a ser difícil para·los Estados Unidos influir en los hechos en ex país. Aún así, es importante que el Congreso y su Comité de Asuntos Exteriores revisen cuidadosamente cualquier pedido posterior de ayuda militar o económica. Toda ayuda a Guatemala debiera ser condicionada a un claro nivel de respeto por lơs regímenes democráticos civiles. 


\section{Conclusión}

El principal mensaje que se desprende de este análisis es muy simple: la existencia formal de un gobierno democrático no garantiza la democracia real. Podríamos desear que la democracia real existiera en El Salvador.y en Guatemala. Desafortunadamente, no es así. Ambos países son democracias formales que esconden estructuras políticas y sociales altamente desiguales, violaciones de los derechos humanos, y espacios políticos limitados para la oposición democrática.

EI Plan Arias es un importante suceso en la región, básicamente porque representa un consenso creciente de que Centroamérica encontrará la paz sólo si los países de la región se mueven hacia la reconciliación nacional y hacia la democratización de sus sistemas políticos. Este es un desarrollo que es bueno para los Estados Unidos y bueno para América Central. A pesar de que las expectativas para el Plan Arias de un éxito total son limitadas, los Estados Unidos podrían ser capaces de construir sobre los principios que ha establecido. En los próximos meses -a medida que se hagan esfuerzos para implementar el Plan Arias- y en el futuro, Estados Unidos debiera usar sus influencias para desmilitarizar la región, estimulando el respeto por los derecho; humanos, y abriendo espacios en el proceso polftico para todas las corrientes políticas dispuestas a jugar de acuerdo a las reglas democráticas. Si è Plan Arias sólo alcanza algunos de sus objetivos, debiéramos darnos por satisfechos de que América Central avanza en la dirección correcta. 